\title{
Chronic peritoneal dialysis in children
}

This article was published in the following Dove Press journal: International Journal of Nephrology and Renovascular Disease 7 October 2015

Number of times this article has been viewed

\author{
Nia Fraser' \\ Farida K Hussain ${ }^{2}$ \\ Roy Connell ${ }^{3}$ \\ Manoj U Shenoy' \\ 'Department of Paediatric Urology, \\ ${ }^{2}$ Paediatric Nephrology, ${ }^{3}$ Paediatric \\ Dialysis, Nottingham University \\ Hospitals NHS Trust, Nottingham, UK
}

Abstract: The incidence of end-stage renal disease in children is increasing. Peritoneal dialysis
(PD) is the modality of choice in many European countries and is increasingly applied worldwide.
PD enables children of all ages to be successfully treated while awaiting the ultimate goal of
renal transplantation. The advantages of PD over other forms of renal replacement therapy are
numerous, in particular the potential for the child to lead a relatively normal life. Indications
for commencing PD, the rationale, preparation of family, technical aspects, and management
of complications are discussed.
Keywords: end-stage renal disease, chronic peritoneal dialysis, renal replacement therapy, pediatric

\section{Introduction}

Chronic peritoneal dialysis (PD) is the dialysis modality of choice for most children with end-stage renal disease (ESRD). ${ }^{1-3}$ Since this condition is relatively rare in children, their care needs to be concentrated in pediatric tertiary centers, where they can benefit from the support of an experienced multidisciplinary team. In the UK, in 2011, a total of 856 children aged under 18 years with ESRD were receiving treatment. Of these, $10.5 \%$ were receiving $\mathrm{PD}$, compared with $9.4 \%$ on hemodialysis (HD) and $80.1 \%$ with a functioning transplant. ${ }^{4}$

Looking at the treatment modality in use at the start of renal replacement therapy (RRT), 48\% were treated with PD, 28\% with HD, and 24\% received a preemptive transplant, demonstrating that PD remains the commonest dialysis modality in children.

Survival of children with ESRD has improved over the last decades, and expert guidance in important clinical areas associated with PD has accumulated, partly due to PD working groups, such as the European Pediatric Peritoneal Dialysis Working Group, and registries, such as the International Pediatric Peritoneal Dialysis Registry. Despite improvements in PD catheter design, better implantation techniques, and advances in training in all aspects of pediatric PD, there are significant risks associated with this form of dialysis.

The potential complications may lead to catheter loss, which may have serious implications for the child. Problems include flow dysfunction, infections, leaks, and intra-abdominal injuries. Complications may be reduced with advanced planning of access placement, attention to detail during insertion, and provision of specialist support for the family. The future of pediatric PD may hinge on research focusing on the peritoneal membrane such as damage prevention, peritoneal membrane cell repair, and stem cell transplantation.
Department of Paediatric Urology, Nottingham University Hospitals NHS Trust, Queens Medical Centre, Derby Rd, Nottingham, NG7 2UH, UK Tel +44 II 59249924 ext 62626 Email nia.fraser@clara.co.uk submit your manuscript $\mid$ www.dovepress.com

Dovepress

http://dx.doi.org/10.2147/IJNRD.S82419
International Journal of Nephrology and Renovascular Disease 2015:8 125-137

(c) (i) (-) 2015 Fraser et al. This work is published by Dove Medical Press Limited, and licensed under Creative Commons Attribution - Non Commercial (unported, v3.0) License. The full terms of the License are available at http://creativecommons.org/licenses/by-nc/3.0/. Non-commercial uses of the work are permitted without any further permission Ior Dove Medical Press Limited, provided the work is properly attributed. Permissions beyond the scope of the License are administered by Dove Medical Press Limited. Information on how to request permission may be found at: http://www.dovepress.com/permissions.php 


\section{Rationale for peritoneal dialysis}

The goals of dialysis are ultrafiltration of blood and the clearance of small and larger molecules. The peritoneum is the dialysis membrane for PD patients. Waste products from the circulation diffuse through the peritoneum into the instilled dialysate, which is then drained from the patient.

Orlow in 1895 showed that in the peritoneal sacs of dogs, solutes not only moved across in accordance with simple osmotic laws, but also by active absorption. ${ }^{5,6}$ Dialysis techniques began to develop, and by the 1940s, uremic patients were treated by instillation after withdrawal of dialysate.

The physiology of dialysis is complex, and one of the most influential factors is capillary permeability. Molecules pass by diffusion and convective mass transport. Aquaporins are responsible for sodium-free water exchange. Small pores allow diffusion to take place, and large pores facilitate convective mass transport. Peritoneal lymphatics also play an absorptive role.

Diffusion capacity depends upon the concentration gradient of solute between plasma and dialysate, along with the solute-specific peritoneal membrane permeability coefficient. Pressure gradients govern ultrafiltration and transport of high molecular weight compounds. The pressure gradient is the sum of osmotic and hydrostatic pressure, which in turn depends on intravascular and intraperitoneal pressure. The surface area available for exchange depends on peritoneal vascular perfusion and the pore density in the capillaries.

\section{PD catheter design}

The first devices used for peritoneal access were drains, trocars, and rubber catheters used in general surgery, urology, and gynecology. In 1947, Pyper described the use of PD in a child with acute nephritis. ${ }^{6}$ While the child reportedly underwent efficient "dialyzation", he did not survive. During the 1960s, Tenckhoff and Schechter introduced a straight, open-ended silastic catheter with perforations ${ }^{7}$ and special features including intra-abdominal, subcutaneous, and external portions along with polyester cuffs bonded onto the catheter at the junctions of these portions. ${ }^{8}$ The cuffs were incorporated to stabilize the catheter by ingrowth of fibroblasts. The concept of home dialysis soon emerged. ${ }^{9}$

There have been many modifications to catheter design since then, including weighted devices to hold the tubing in the pelvis. ${ }^{8,10}$ Other adaptations include immobilizer devices and catheters with longer tubing designed for specific situations. ${ }^{11}$ There is no firm agreement on optimum catheter configuration. Data from the North American Pediatric Renal Transplant Cooperative Study registry suggest that children should be treated with swan-neck type catheters with two cuffs. ${ }^{12}$ At the authors' institution, coiled double- cuffed catheters, such as the Swan Neck Pediatric Curl Cath (Argyle, Covidien, Dublin, Ireland), are preferred. Pediatric sizes (from the cuff to the curled tip) are $42 \mathrm{~cm}$ and $62.5 \mathrm{~cm}$ in length. For infants, a shorter ( $23 \mathrm{~cm}$ cuff to tip) catheter is available (Flexneck classic coiled infant).

\section{Choice of therapy and when to start}

All patients and their families should be well prepared for dialysis. This is best achieved within a multidisciplinary setting. ${ }^{13}$ The advantages of PD over HD include the following.

PD is a home-based therapy that achieves more steadystate biochemical control and is therefore less likely to cause symptoms. It may be technically easier in the infant population and avoids the need for venous access. Family preference and other medical or social factors should always be taken into consideration. Disadvantages include the increased burden of responsibility on carers and risk of infection.

Indications for ESRD therapy include a combination of biochemical and clinical characteristics, with the aim being to commence RRT early enough to prevent malnutrition and uremic symptoms. Guidelines state that RRT should commence when a patient has an estimated glomerular filtration rate $<15 \mathrm{~mL} / \mathrm{min} / 1.73 \mathrm{~m}^{2}$ with symptoms or signs of uremia, fluid overload, or malnutrition, or before an asymptomatic patient has an estimated glomerular filtration rate of $<6 \mathrm{~mL} / \mathrm{min} / 1.73 \mathrm{~m}^{2} .{ }^{14}$

\section{Preparation of the child and family}

After discussing the RRT options with the child and its family, an opportunity to visit the dialysis services is arranged. This allows a more informed decision to be made about which modality is best suited for the child. It also introduces them to other RRT facilities, including the HD area, in case conversion to HD is required in the future. A home visit is carried out to assess the suitability of the patient's home for PD and provides a more relaxed atmosphere for discussing the changes ahead. If available, a play specialist should attend to assist in preparing the child, using written and pictorial information, a DVD, and dolls to aid demonstration of the catheters. ${ }^{13}$

When a decision is reached about $\mathrm{PD}$, appropriate psychosocial input should be offered to the family to allow any fears to be discussed, and hopefully alleviated, prior to commencing therapy. Anxieties about commencing dialysis can vary, and sometimes simple and practical issues are at the forefront of the parents' concern. We suggest that a visit by the renal social worker is essential for families requiring support, as parents often converse more freely with a nonmedical mem- 
ber of the team. ${ }^{1}$ Careful monitoring of electrolytes between surgery and commencement of PD is vital.

\section{Prescription of PD fluids}

There is no optimal PD fluid prescription applicable for all children, and the type of fluid, together with dwell time, is determined on an individual basis. Changing needs, such as growth of the child, is taken into account, and the prescription adjusted accordingly. The exchange fill volume of dialysate is calculated according to body surface area, not weight. In children younger than 2 years, the fill volume prescription is based more on tolerance than on optimal dialytic exchange volume. A suggested fill volume is approximately $800 \mathrm{~mL} / \mathrm{m}^{2} .{ }^{15}$ This volume is usually tolerated well, and can be increased stepwise to achieve efficient exchange. Children older than 2 years would be expected to cope with fill volumes close to $1200-1400 \mathrm{~mL} / \mathrm{m}^{2}$. High osmolality, acidity, and high lactate content have been associated with deleterious effects on peritoneal structure and function, resulting in ultrafiltration failure. The lowest glucose concentration and number of cycles possible to achieve adequate ultrafiltration should be used. ${ }^{15}$ Use of certain types of PD fluids may be associated with inflow pain, and there are studies comparing the biocompatibility of different solutions. ${ }^{16}$ The commonly used PD fluids are listed in Table 1 and summarized below.

\section{Dianeal PD4}

Until recently, this was the standard fluid for commencing and maintaining patients on PD, unless otherwise biochemically indicated.

\section{Physioneal 40}

This is a frequently used and more biocompatible fluid for commencing and maintaining patients on PD when a lower lactate fluid is required. The neutral $\mathrm{pH}$ avoids infusion pain.

\section{Physioneal 35}

This is also a more biocompatible fluid, especially useful in hypocalcemic patients or those requiring a fluid with reduced lactate.

\section{Extraneal}

This is a polyglucose-based fluid for use in patients requiring a prolonged dwell time for fluid removal and/or solute clearance. This fluid should be used in conjunction with other glucose-based fluids (Dianeal and/or Physioneal) and can be used with Nutrineal if required.

\section{Nutrineal PD4 I.1\%}

This is ideal for patients needing nutritional supplementation, and is used as a prolonged dwell when the patient is receiving their main meal of the day. It should be used in conjunction with glucose-based fluids (Dianeal and/or Physioneal), and can be also be used with Extraneal.

\section{Peritoneal dialysis techniques}

Automated peritoneal dialysis (APD) is the most common form used in pediatrics. Typically, patients connect to a machine in their bedroom overnight which "cycles" fluid in and out, usually on a 1-2-hour basis. This means that they are free from dialysis during the day, making it ideal for children to continue school, daily routines, and social interaction. The standard regimen is 10 hours of APD in older children and 12 hours in infants. The machines and fluids are portable, making traveling and holidays possible. For some patients, particularly those who have lost residual renal function, a daytime dwell is added.

Table I Peritoneal dialysis fluids used in the UK

\begin{tabular}{|c|c|c|c|c|c|}
\hline & Dianeal PD4 & Physioneal 40 & Physioneal 35 & Extraneal & Nutrineal I.I\% \\
\hline $\mathrm{Na}(\mathrm{mmol} / \mathrm{L})$ & 132 & 132 & 132 & 133 & 132 \\
\hline $\mathrm{Ca}(\mathrm{mmol} / \mathrm{L})$ & 1.25 & 1.25 & 1.75 & 1.75 & 1.25 \\
\hline $\mathrm{Mg}(\mathrm{mmol} / \mathrm{L})$ & 0.25 & 0.25 & 0.25 & 0.25 & 0.25 \\
\hline $\mathrm{Cl}(\mathrm{mmol} / \mathrm{L})$ & 95 & 95 & 101 & 96 & 105 \\
\hline Lactate $(\mathrm{mmol} / \mathrm{L})$ & 40 & 15 & 10 & 40 & 40 \\
\hline Bicarbonate $(\mathrm{mmol} / \mathrm{L})$ & 0 & 25 & 25 & 0 & 0 \\
\hline Osmotic agent & Glucose & Glucose & Glucose & Icodextrin & Amino acid \\
\hline \multirow[t]{3}{*}{ Strengths } & $13.6 \mathrm{~g} / \mathrm{L}$ & $13.6 \mathrm{~g} / \mathrm{L}$ & $13.6 \mathrm{~g} / \mathrm{L}$ & $7.5 \mathrm{~g} / \mathrm{L}$ & $87 \mathrm{mmol} / \mathrm{L}$ \\
\hline & $22.7 \mathrm{~g} / \mathrm{L}$ & $22.7 \mathrm{~g} / \mathrm{L}$ & $22.7 \mathrm{~g} / \mathrm{L}$ & & \\
\hline & $38.6 \mathrm{~g} / \mathrm{L}$ & $38.6 \mathrm{~g} / \mathrm{L}$ & $38.6 \mathrm{~g} / \mathrm{L}$ & & \\
\hline \multirow[t]{3}{*}{ Osmolality mOsm/L } & 344 & 344 & 345 & 284 & 365 \\
\hline & 395 & 395 & 396 & & \\
\hline & 483 & 483 & 484 & & \\
\hline $\mathrm{pH}$ & 5.5 & 7.4 & 7.4 & 5.5 & 6.7 \\
\hline
\end{tabular}


In continuous ambulatory $\mathrm{PD}$, dialysate is constantly present within the abdomen, and several exchanges (typically four) are undertaken during the day. This allows a greater length of time for fluid to remain within the abdomen. More than four exchanges is unnecessary in children, and very likely would cause excessive disruption to the child's daily routines and education. In a proportion of patients who are not achieving adequate clearances, a combination of the two, such as APD with an added daytime exchange, is preferable.

Many teenagers are reluctant to be attached to a PD machine for lengthy periods of time and want to stay out later, so a compromise in therapy is sometimes required. If continuous ambulatory PD is burdensome, a combination of the two therapies can be used, allowing a shorter cycling time overnight plus an exchange during the day after school.

Little difference in efficacy has been shown between the two forms of PD. In children under 2 years of age and in those receiving a liquid-only diet (gastrostomy or nasogastric tube-fed children), APD is recommended. ${ }^{13}$

Children with decreased or no urine output requiring a higher degree of fluid removal will benefit from shorter dwell times to maximize ultrafiltration. However, a balance between this and solute removal alongside electrolyte balance is required.

The membrane characteristics of the patient can be assessed by undertaking a peritoneal equilibration test (PET). It is recommended that this should be done within 6 weeks of commencing PD, and annually thereafter (sooner if the patient develops peritonitis or is not achieving expected clearances). ${ }^{14}$

\section{Peritoneal equilibration test}

The PET is performed to determine peritoneal membrane characteristics that give an indication of solute transport function. ${ }^{17}$ The test tells the clinician how quickly or slowly solutes move across the peritoneum, which guides the dialysis prescription. The PET is widely used in adults, but due to the lengthy procedure involved and disparity seen in test results in children, this test is not performed routinely in pediatric renal units in the UK.

This test measures two aspects of membrane function, ie, low molecular weight solute transport and ultrafiltration capacity. The former is expressed as the dialysate, ie, dialysate-to-plasma ratio of creatinine at 4 hours (D/P creatinine). It allows longitudinal comparison within individuals and comparison between patients. Patients are then categorized into one of the following groups:
- High transporters (creatinine $\mathrm{D} / \mathrm{P}>+1$ standard deviation [SD] from the mean). These patients achieve the most rapid equilibration for urea and creatinine, but lose their osmotic gradient for ultrafiltration rapidly, and are more suited to frequent short-duration dwells (or APD).

- Low transporters (creatinine $\mathrm{D} / \mathrm{P}<1 \mathrm{SD}$ from the mean). These patients have slower and less complete equilibration for urea and creatinine, but good ultrafiltration, and benefit from longer high-volume dwells (continuous ambulatory PD).

- High-average transporters and low-average transporters (creatinine $\mathrm{D} / \mathrm{P}+1 \mathrm{SD}$ to $-1 \mathrm{SD}$ around the mean). These patients are in between the above two groups clinically.

\section{Surgical aspects of PD placement}

The ideal method for inserting PD catheters remains controversial, and currently their success may depend more on placement technique than on catheter design..$^{18}$ The aim is to place the intra-abdominal portion of the catheter into the pelvis, free from structures that may cause entanglement and blockage. Tunneling of the catheter up to and through the skin allows formation of an exit site. The superficial cuff should be situated approximately $2 \mathrm{~cm}$ from the exit site. ${ }^{8}$ Ideally, the exit should be placed on the left abdominal wall to avoid the site of future renal transplant, often placed in the right iliac fossa. ${ }^{19}$ In our practice, we have found that this site is suitable in many children who have or who may later require a gastrostomy. It is also reasonable for the PD to be sited at the right upper quadrant in these children, in keeping with 2012 consensus guidelines. ${ }^{20}$ Preoperative skin marking can be useful, to help avoid existing stomas and the belt and nappy areas.

It is important to ensure that sufficient tube length remains above the level of the skin to allow application of connector systems and dialysate bags. The catheter should be tested for patency and leaks, irrigated until clear, then filled with heparinized saline (10 U/mL is adequate) to prevent clot formation and capped off. Exit sutures are not recommended, but anchoring devices such as dressings should be applied to immobilize the catheter.

\section{Techniques for PD catheter placement}

The three main commonly employed methods for insertion of a PD catheter are the laparoscopic-assisted, open (mini-laparotomy), and percutaneous (trocar or Seldinger) techniques. Surgeon preference, availability of equipment, and individual patient factors are important in the approach used to place the catheter. 


\section{Laparoscopic approach}

Laparoscopic-assisted insertion of PD catheters has become popular over recent years. At our unit, we prefer the laparoscopic approach with omentectomy as described by Najmaldin. ${ }^{21}$ In this procedure, a single supraumbilical incision is made through which as much omentum as possible is delivered and resected. In children, the omentum is flimsy and easy to manipulate through a small incision. Following pneumoperitoneum, a laparoscope is inserted. A needle and guide wire is introduced to create a long extraperitoneal tunnel, through which a peel-away sheath (split cannula system) is passed. After the introducer and guide wire are removed from the lumen of the cannula, the PD catheter is passed down and directed into the pelvis. The long tunnel fixes and stabilizes the catheter, making the tip less likely to flip upward. The catheter is tunneled using a gentle curve in a caudolateral direction, and passed downward-facing to a suitable skin site. The umbilical fascia and skin is closed, to attain as watertight a closure as possible (Figure 1).

Other laparoscopic techniques have also been described, including gasless laparoscopy ${ }^{22}$ omental fixation to the abdominal wall or falciform ligament (omentopexy), or shortened by folding then suturing onto itself (omental folding). ${ }^{23}$

There are significant advantages with the laparoscopic approach. Laparoscopy allows inspection of the peritoneal cavity, including hernial orifices. Exact positioning of the catheter can be achieved, and adequacy of omentectomy can be checked. In addition, the smaller diameter of the peritoneal perforation produced by the peel-away sheath and elastic sealing of the insertion site may be advantageous. ${ }^{24}$ Other procedures may also be performed laparoscopically at the same sitting such as nephrectomy, gastrostomy insertion, and herniotomy. In our experience, children who undergo
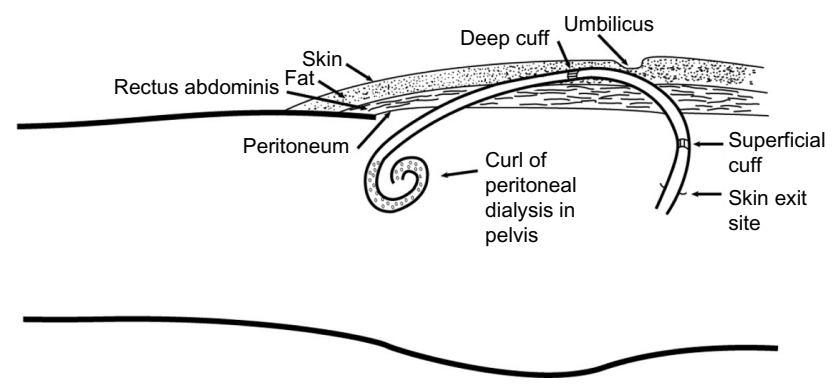

Figure I Position of peritoneal dialysis catheter within oblique musculofascial tunnel and position of the cuffs. simultaneous laparoscopic PD catheter and gastrostomy insertion do not have an increased incidence of catheterrelated peritonitis. ${ }^{25}$

The laparoscopic approach may even be suitable in children who have adhesions following previous abdominal surgery. ${ }^{26}$ Laparoscopic adhesiolysis may be necessary in order to create a suitable space for the PD catheter. ${ }^{19}$

\section{Open approach}

A small incision is placed above or below the umbilicus, a partial omentectomy is undertaken, and the catheter is directed into the pelvis.

\section{Percutaneous approach}

A needle puncture is performed into the peritoneum, aspirating to ensure no visceral injury has occurred, and a guide wire is passed. After dilatation of the tract, the catheter is advanced toward the pelvis.

\section{Special situations} Infants and small children

Additional challenges are posed by infants and small children, due to the thinness of the abdominal muscle layers. This potentially increases the difficulty in obtaining durable catheter fixation and a liquid-tight peritoneal closure. A high proportion of under 2-year-olds commence PD in preference to HD, ie, two thirds in the UK Renal Registry 15th Annual Report in 2013, ${ }^{4}$ and higher in some series. In this age group, catheter-related complications are more common, with peritonitis rates of one per 10.3 patient months (compared with a standard of one per 14 patient months in children). Catheter loss is common (one per 8.3 patient months in a previous study at our center). ${ }^{27}$ Rinaldi et al noted significantly worse catheter survival in infants younger than 6 months. ${ }^{28}$

\section{Abdominal wall abnormalities}

Successful PD has been reported in children with congenital abdominal wall anomalies such as prune belly syndrome, ${ }^{29}$ exomphalos, and gastroschisis-type defects. The deficiency of the abdominal wall in children with prune belly syndrome may predispose to a less robust extraperitoneal tunnel. Often the cuff is much wider than the muscle into which it is placed, and some shave the cuff to reduce its bulk in these children. Also, in patients with prune belly syndrome, the PD fluid may cause a sensation of abdominal swaying during walking. This may be overcome by reducing the volume of dialysate. ${ }^{29}$ 
Existence of a congenital diaphragmatic hernia may not be a contraindication to PD, and successful dialysis has been reported in a preterm baby with acute renal injury. ${ }^{30}$

\section{Abdominal wall sepsis}

Modifications in choice of exit site include situations where exit onto the abdominal wall is difficult such as in children with significant abdominal wall sepsis. The catheter can be tunneled presternally, with exit onto the chest wall. This is also popular in PD patients who wish to use hot tubs. ${ }^{11}$ The upper chest reportedly has minimal wall motion during normal daily activities, so decreased piston-like movement at the exit site may make inward transfer of microbes less likely. Some authors using this method warn that the implantation technique is more challenging and additional tube length reduces the flow of dialysate slightly. Extra slack in the tunnel portion of the catheter is required in children to accommodate future growth. Despite this, the two parts may become disconnected due to rapid growth or trauma. ${ }^{31}$

\section{Children with other comorbidities}

Successful PD has been reported in children with ventriculoperitoneal shunts, and can be considered a good option in those with cerebral palsy, Down syndrome, or social disadvantage. ${ }^{32}$

\section{Postoperative care and use of PD catheter \\ Exit site care}

Postoperatively, the sterile dressings are left undisturbed for a week (unless soiled). After this, it is recommended that sterile dressings are applied to the exit site once a week following cleaning. The catheter should be immobilized to prevent local torqueing movement. Dressing changes should be continued for at least 2-3 weeks. Application of a topical antibiotic has been recommended by some, although it is unclear whether this is truly beneficial. ${ }^{20}$ Cleaning agents vary between units; saline is comparable in its effectiveness to other cleaning agents. Showering is avoided within the first 2 weeks after insertion, and after this it can be undertaken as normal, with care taken to dry the site thoroughly afterwards.

\section{Initiation of PD}

Dialysis can be commenced on the same day as the operation if desired, although it is usual to allow a rest period of 1-2 weeks before first use. Immediate use is ideal for children in whom dialysis dependency occurs more rapidly than anticipated. Catheters used early (within days) have been reported to have more mechanical problems than those accessed later, but many now advocate early use. ${ }^{33}$ Commencing PD for the first time should be done with reduced cycle volumes (approximately $10 \mathrm{~mL} / \mathrm{kg}$ ) to assess the functionality of the catheter without putting too much pressure on the wounds. The fill volume can be increased over the next few days, commensurate with patient tolerance. Inflow and outflow are closely observed, as well as early problems such as leaks. Small solute clearances along with residual urine should be measured at least 6 monthly, with a combined urinary and peritoneal Kt/V (urea) of 1.7 per week or a creatinine clearance of $50 \mathrm{~L} /$ week $/ 1.73 \mathrm{~m}^{2}$ being considered the minimum treatment dose. Patients (particularly if anuric) who achieve a daily ultrafiltration rate of less than $750 \mathrm{~mL} / 1.73 \mathrm{~m}^{2}$ should be closely monitored and considered for a switch in dialysis modality.

\section{Training and support for patient and parents}

Children on PD have problems that are fundamentally different from those in adults on PD. Specific issues such as nutrition, growth, gastrostomies, and behavioral changes need to be managed. The expertise of a specialist pediatric PD nurse is paramount in the ongoing care of the child and family. Improvement in measurable outcomes such as infection rates was emphasized by Gunasekara et al in a study comparing cohorts of children with input from specifically trained pediatric nurse specialists with those without. ${ }^{34}$

Learning about PD is not a one-speed function, and discussion with the carers should be continuous through the training period to ensure an adequate understanding is being achieved. Prior to discharge, a period of time should be spent in a family unit away from the hospital to encourage confidence. The average training time for children and their families is approximately 5-7 days, with the majority of teaching being performed in-center ${ }^{20}$ and some at home.

\section{Complications in children receiving PD}

Despite commonly employed measures to improve PD outcomes, complications are common. Infection remains the most significant cause of morbidity in children receiving chronic PD, and the frequency of peritonitis in children exceeds that in adults. Peritonitis is the most common reason for changing dialysis modality. Other potential complications include mechanical flow dysfunction, which may be due to blockage or kinking of the tubing, or migration of the tip. Dialysate leaks, bleeding complications, and hernia of the 
abdominal wall are relatively common, and rarer events, such as bowel perforation or injury to intra-abdominal structures, can occur. ${ }^{8}$

\section{Mortality}

Mortality as a direct result of PD is rare, and it is well established that the mortality of dialyzed children is decreasing. ${ }^{35}$ In a study by Phan et al, the overall mortality in a cohort of children undergoing chronic $\mathrm{PD}$ was $7 \% .{ }^{3}$ Children requiring RRT at a young age have been shown to have greater mortality than older children. Non-renal comorbidities are known to be major contributors to mortality. ${ }^{36}$ In a study by Laakkonen et al, mortality was $9 \%$ for children under the age of 2 years while on the PD program (most had Finnish type congenital nephrotic syndrome). ${ }^{37}$ Schroff et al in 2006 reported a mortality rate of $10 \%$ for younger children during dialysis and $17 \%$ during their entire follow-up period, giving a relative risk of death 2.7 times higher than that of older dialyzed children. ${ }^{38}$

\section{Peritonitis}

Although PD-related peritonitis has decreased since the late 1980s, peritonitis remains the major complication of PD. Children on PD with peritonitis present with cloudy effluent and abdominal pain. Other symptoms include fever, rigors, anorexia, vomiting, abdominal distension, and septic shock. To make the diagnosis early, peritonitis should be considered whenever the peritoneal effluent is cloudy. Other diagnoses for the acute abdomen should also be considered. Appendicitis, peptic ulceration, pancreatitis, inflammatory bowel disease, and ovarian pathology have been encountered in children on PD. The differential diagnosis of cloudy effluent includes chemical or eosinophilic peritonitis, presence of blood or fibrin, specimen taken from a "dry" abdomen, rarely malignancy, and chylous ascites. Leukocyte esterase reagent test strips can be used as a simple screening test for the presence of white blood cells in the drained fluid. An effluent white cell count exceeding $100 / \mathrm{mm}^{3}$ with differential of at least $50 \%$ neutrophils is highly suggestive of peritonitis. There may be growth of Gram-positive organisms, Gram-negative organisms, or slow-growing bacteria or yeasts. Culture-negative peritonitis is also possible. Risk factors for peritonitis include exit site infection (ESI), ${ }^{20}$ young age, low urine volume, low residual renal function, and immunosuppression.

\section{Treatment}

Intraperitoneal administration is the route of choice for most antibiotics, ${ }^{20}$ because high bactericidal concentrations are immediately established at the infection site. Therapeutic blood levels are achieved via absorption from the peritoneal cavity. Most dosing regimens include a prolonged initial dwell cycle, followed by maintenance dosing. The choice of antibiotic depends on the organism grown and local resistance patterns, but often includes a glycopeptide (vancomycin or teicoplanin), or beta-lactam such as a cephalosporin. A treatment duration of 2 weeks is advisable, unless the organism is Staphylococcus aureus, in which case, 3 weeks of antibiotics are required. Improvement of symptoms and clearing of effluent usually occur within 72 hours. If there is no demonstrable improvement, reevaluation should include repeat peritoneal fluid cell count, Gram stain and culture, and thorough examination for other sources of infection such as intra-abdominal abscess or tunnel infection (TI).

\section{Relapsing peritonitis}

This is defined as a second peritonitis episode with the same organism (or sterile culture) within 4 weeks of completion of therapy for a prior episode. The overall incidence is approximately $10 \%-20 \%$ of peritonitis episodes. Lane et al reported that young age, a single-cuff catheter, a downward-pointing exit site (not supported in other series), and chronic systemic antibiotics were independent risk factors for relapsing peritonitis in their multivariate analysis. ${ }^{39}$ Children with recurrence of peritonitis have significantly decreasing peritoneal solute transport and PET scaling. Recommended treatments include intraperitoneal beta-lactam antibiotics and consideration of the susceptibilities of the original bacteria. An intraluminal fibrinolytic agent (urokinase $1,000 \mathrm{IU} / \mathrm{mL}$ or $5,000 \mathrm{IU} / \mathrm{mL}$ ) or recombinant tissue plasminogen activator $(1 \mathrm{mg} / \mathrm{mL})$ may be helpful. ${ }^{20}$ This is assuming that there is no ESI or TI. Williams et al, however, found that replacement of the catheter instead of urokinase therapy led to fewer repeat episodes. ${ }^{40}$ Decreased macrophage bactericidal activity, opsonic activity, and immunoglobulin $\mathrm{G}$ concentration of peritoneal effluent have been found in children with a high rate of peritonitis.

\section{Culture-negative peritonitis}

It has been recommended that if the initial cultures remain sterile at 72 hours and if signs and symptoms of peritonitis are improving, empiric antibiotic therapy (cephalosporin or glycopeptide) should be continued for 2 weeks.

\section{Persistent (refractory) peritonitis}

Catheter exchange has been shown to be superior to urokinase in lowering the treatment failure rate in both relapsing and 
refractory peritonitis. Certain select individuals (eg, infants with documented hypogammaglobulinemia) may be considered for treatment with intraperitoneal or intravenous immunoglobulin $\mathrm{G},{ }^{20}$ but guidance on its use in those with normal immunological workup is lacking. It is well recognized that prolonged attempts to treat refractory peritonitis and to save the catheter must be avoided to prevent a poor patient outcome.

\section{Fungal peritonitis}

Fungal pathogens account for approximately 5\% of cases of peritonitis. Fungal peritonitis can follow episodes of bacterial peritonitis, especially if caused by Gram-negative organisms. Recent antibiotics and immunosuppression are also risk factors. It should be suspected if the patient has few clinical symptoms but persistent cloudy effluent. Children should undergo early removal of the catheter with an appropriate dose of oral or intravenous antifungal treatment, depending on local microbiology policy. Reinsertion of the PD catheter can be considered after a minimum period of approximately 2 weeks, in keeping with International Society for Peritoneal Dialysis recommendations.

\section{Eosinophilic peritonitis}

Eosinophilic peritonitis is also a recognized complication of PD in children. It is usually defined as a peritoneal fluid white cell count greater than 100 cells $/ \mathrm{mL}$ ( or $0.1 \times 10^{9}$ cells $/ \mathrm{L}$ ) with $\geq 10 \%$ eosinophils. ${ }^{41}$ In $60 \%$ of affected patients, there is an associated peripheral blood eosinophilia. In a recent retrospective UK study, eosinophilic peritonitis represented a third of cases of culture-negative peritonitis in a cohort of children undergoing PD. Despite commonly presenting with cloudy effluent only, eosinophilic peritonitis can be associated with abdominal pain. The pathophysiology of eosinophilic peritonitis is unclear, but possible precipitants include hypersensitivity to the PD tubing or dialysate, pneumoperitoneum if the insertion was laparoscopic-assisted, and rapid fluctuations in peritoneal osmolality and infection. There is a paucity of evidence-based treatment guidelines in the pediatric literature, but options supported by case reports include change in dialysate or PD modality, antihistamines, intraperitoneal hydrocortisone, and oral montelukast, a leukotriene receptor antagonist. ${ }^{42}$ Its course can be self-limiting, but there is also a risk of development of chronic or recurrent eosinophilic peritonitis, and irreversible changes in membrane function.

\section{Prevention}

Consensus guidelines for the prevention and treatment of catheter-related infections and peritonitis have been published. ${ }^{20}$ Prevention strategies previously focused primarily on antimicrobial prophylaxis. Interventions that have been studied include modification of catheter design, implantation techniques, connection methods, and PD modality. Recognition of contamination at the time of exchange and implementation of appropriate measures to reduce the risk of peritonitis are essential. Parental training in particular must emphasize prompt recognition and prevention of peritonitis.

\section{Catheter-related factors}

Data from the 2008 North American Pediatric Renal Trials and Collaborative Studies report demonstrated that use of the double-cuff curled catheter with a swan-neck tunnel and a downward-directed exit site was associated with a better annualized peritonitis rate and longer time to first episode compared with other combinations of catheter characteristics. ESI predisposes to peritonitis, ${ }^{20}$ and measures should be taken to prevent this complication. Antimicrobial-coated catheters have been developed in the biomaterials laboratory at our center, and prolonged activity against common PD pathogens has been demonstrated in these catheters. ${ }^{43}$

\section{Antibiotic prophylaxis}

Administration of an antibiotic just before PD catheter placement has been shown to lower the incidence of early infections in both retrospective and prospective studies. ${ }^{20}$ The choice of antibiotic to be used should also take into account the center-specific susceptibility patterns and the prevalence of vancomycin-resistant enterococci.

\section{Connection procedures}

Luer lock connection technology has replaced manual spiking of dialysate bags in most centers, with the aim of avoiding touch contamination. A systematic review of randomized controlled trials revealed that use of a Y-set system (compared with the spike system) was associated with a significantly lower risk of peritonitis. ${ }^{44}$ In the twin-bags and Y-set systems, dialysate solutions and drain bags are both attached prior to the procedure. These flush out possible contaminants during attachment more effectively.

\section{Monitoring of peritonitis}

All PD-related infections should be monitored by the center at least annually, including organisms grown, antibiotic sensitivities, and predisposing factors. Calculations based on peritonitis episodes per year and number of episodes per patient month can be monitored. 


\section{Exit site and tunnel infections}

ESI and TI are common in pediatric PD patients. Clinical signs include redness, swelling, and purulent discharge from the exit site and along the path of the PD tubing in the subcutaneous plane in TI. These cause significant morbidity because of the risk of peritonitis, hospitalization, and need for access revision. ESI attributable to $S$. aureus and Pseudomonas aeruginosa are particularly associated with concomitant TI and subsequent peritonitis. In these cases, treatment of the infection should be aggressive, because the peritonitis can be very treatment-resistant. These organisms form a biofilm on the catheter, thereby precluding successful eradication with antibiotics.

For ESI without tunnel involvement, 2 weeks of oral antibiotics after culture and a further 1 week after complete resolution of infection should suffice. In cases where ESI shows no improvement, a change of PD catheter should be considered, although an alternative approach would be to shave the external cuff and form a separate tunnel and exit site. TI should be treated for 2-4 weeks, intravenously or intraperitoneally if necessary.

ESI prophylaxis has been advocated by some, given that S. aureus carriage is a well-documented risk for exit site colonization and subsequent infection. Mupirocin applied to the exit site or intranasally may be advantageous, but data to support this have mainly been obtained from adults ${ }^{45}$ Recently, the emergence of mupirocin-resistant S. aureus in PD patients has brought this prophylactic strategy into question.

\section{Recommendations for catheter removal, or removal and simultaneous replacement}

Removal of the PD catheter is recommended in the following situations: refractory bacterial peritonitis, fungal peritonitis, and persistent ESI or TI despite appropriate treatment, especially in conjunction with peritonitis involving the same bacteria. Simultaneous catheter removal and replacement would be suitable options for refractory ESI or TI and after clearing of the peritoneal effluent in relapsing bacterial peritonitis. Removal of the PD catheter is best performed under general anesthesia in children. We recommend approaching the tubing via the incision (usually umbilical) closest to the deep cuff. Both cuffs can be freed and the fascia closed securely, thereby avoiding subsequent incisional hernia. Very rarely, an open defect may risk ischemic bowel incarceration, similar to that reported by Wong et al. ${ }^{46}$

\section{PD catheter blockage}

Causes of blockage include entanglement by the greater omentum if not excised during PD placement, or less commonly by the ovary, fallopian tube, small intestine and, in older children, appendices epiploicae. Like other authors, we strongly recommend prophylactic omentectomy during insertion of the PD catheter, as failure to perform this is associated with a higher rate of catheter failure and reoperation. ${ }^{47}$ If omental wrapping has caused catheter blockage, freeing of the catheter and omentectomy can be performed. Obstruction by residual omentum can occur if omentopexy rather than omentectomy is performed. Other causes of blockage include occlusion of the lumen by a blood clot, which can be treated with fibrinolytics or kinked tubing. Sometimes revision is required.

\section{Tube migration}

The tip of the PD tube can become displaced to unsuitable sites such as near the liver or spleen. In this situation, failure of drainage is common. A plain radiograph may be useful to confirm the tube position. Inducing vigorous bowel peristalsis with laxatives or enemas may help. The long extraperitoneal tunnel created during tube insertion should make its position stable. Some surgeons place internal sutures to fix the catheters in place during implantation. ${ }^{48}$ If the tube has moved, it may be amenable to fluoroscopic or laparoscopic repositioning.

\section{Overgranulation of exit site}

Exuberant granulation tissue can form at the exit site. This can be cauterized cautiously by silver nitrate. Measures to immobilize the catheter and protect the exit site from trauma should be applied.

\section{Leaks}

Dialysate leaks are one of the most frequent noninfectious complications of PD. ${ }^{49}$ Pericatheter leaks are the most common. Leaks are significantly less common in laparoscopic procedures, due to the snug fit of the catheter at the peritoneal level and a long musculofascial tunnel,,$^{50}$ even if the catheters are used immediately. Higher volume leaks may be caused by a large tear in the peritoneum, most likely if a trocar has been employed. Repair of the peritoneum can be performed without loss of the catheter. If the peritoneal tear is near the inguinal region, marked genital edema can occur. ${ }^{51}$ Application of fibrin glue at the exit site can prevent early leaks. ${ }^{52}$ Rarely, extra-abdominal leak may cause hydrothorax or pericardial effusion. ${ }^{53,54}$ Weight gain and loss 
of ultrafiltration occur. Hydrothorax has been reported in a child with previously undiagnosed congenital diaphragmatic hernia. ${ }^{55}$ In this condition, the pleuroperitoneal canals fail to fuse around gestational week 8 , resulting in a communication between the thoracic and abdominal cavity. Left-sided defects are the most common. The dialysate escapes into the pleural space, causing an effusion and respiratory compromise. In general, if there is a significant leak at any site, treatment options are to use lower dialysate volumes, perform PD with a cycler, rest the catheter, or temporary switch to HD.

\section{Bleeding}

Coagulopathies should be corrected preoperatively, and intraoperative blood products also given if indicated. Minor bloodstained effluent is common during early use of the PD catheter, and results from tearing of small adhesions. Brisk bleeding may occur if intra-abdominal injury has been sustained. Fortunately, this is now rare with improved surgical techniques, less trocar use, and manufacture of softer catheters. Large intraperitoneal hematomas may interfere with dialysate exchange, and may require surgical revision. Bleeding may arise from the subcutaneous track if the inferior epigastric vessels are injured. If there is no resolution with direct pressure over the tunnel and exit site, the wound should be explored and the catheter exchanged if unavoidable. Tunnel hematoma noted post implantation should be treated with antibiotics, as this may reduce the chance of TI and abscess. ${ }^{1}$

\section{Cuff extrusion}

Cuff extrusion is uncommon, but may be a consequence if during implantation the tract is placed just under the skin rather than in the fat plane (or if the fat plane is attenuated, as in a neonate, malnourished child, or child with prune belly syndrome). If the external cuff exteriorizes, this will predispose to tube dislodgment, especially if it occurs early. It may also be seen in conjunction with ESI or TI. In this situation, the PD catheter may be salvaged by cuff shaving or techniques, which essentially replace the superficial portion of tube only. ${ }^{56}$ If symptoms associated with the cuff are refractory, or if the tube becomes breached, a revision is required.

\section{Abdominal wall hernias}

Hernias are common in children undergoing chronic PD. The incidence of all types of hernia may be as high as $50 \%$, or greater. ${ }^{57}$ These include inguinal, umbilical, epigastric, and incisional hernias. The highest incidence is seen in infants and small children, ${ }^{57}$ and this may be explained by the more fragile abdominal wall and inguinal structures. Most inguinal hernias occur within the first few months following initiation of dialysis. In a study by Dönmez et al, no correlation was observed between development of hernia and early versus delayed catheter use. ${ }^{58}$ Once diagnosed, repair is recommended, and lower dialysate volumes or alternative PD regimes may be advisable while awaiting repair. Some surgeons close the internal ring (thereby preventing clinical hernia) if it is found to be open during laparoscopic PD catheter placement. ${ }^{24,59}$

\section{Encapsulating peritoneal sclerosis}

In encapsulating peritoneal sclerosis (EPS), there is diffuse and marked thickening of the peritoneal membrane. The bowels become cocooned in a restrictive fibrocollagenous sheath and may become obstructed. EPS can be associated with high mortality, ${ }^{60}$ but in children this is rare. The child is usually unwell, with abdominal symptoms and signs of bowel obstruction. Poor ultrafiltration is commonly seen, and PD should be discontinued. A computed tomography scan, if performed, may demonstrate calcification of the peritoneum. EPS is a histological diagnosis, and changes include increased levels of type IV collagen, fibroblasts, myofibroblasts, and microvasculature. ${ }^{61}$ Long-term PD is the most important risk factor for EPS, especially if used for over 5 years. Transfer to HD almost invariably occurs, and surgery may be required, comprising adhesiolysis and excision of the fibrous membrane. Postoperatively, there may be prolonged ileus, and total parenteral nutrition may be a necessity. Other treatments have been described in children with EPS, including systemic high-dose corticosteroids and immunosuppressants such as azathioprine. ${ }^{62,63}$

\section{Growth in children on PD}

Growth retardation is a complication associated with ESRD. When compared with children who have a functioning renal transplant, dialyzed children have reduced median $\mathrm{z}$ scores for height $(-2.0$ versus -1.3$)$ and weight ( -1.2 versus -0.2) ${ }^{64}$ In comparison with HD, children on a PD program have improved $\mathrm{z}$ scores for height, particularly those who are younger than 6 years old at commencement of RRT. ${ }^{65}$ Nutritional assessment and input from a pediatric dietician are essential. In the majority of younger children, a gastrostomy is needed, and can be placed either at the same time as PD catheter placement or on a separate occasion, with the aim of boosting nutrition and growth prior to transplant.

\section{Future of PD in children}

Prevention and repair of peritoneal damage is a critical mission in PD. The monolayer of multipotent mesenchymal 
cells, which line the peritoneal membrane, has been shown to play a key role in peritoneal homeostasis and immune regulation. Transplantation of mesothelial cells has been suggested to reduce peritoneal injury during PD. Profibrotic factors, such as transforming growth factor beta, have been implicated in peritoneal fibrosis, and promising studies have shown that mesenchymal stem cells ameliorate experimental fibrosis by suppressing transforming growth factor beta-1 signaling in a paracrine fashion. ${ }^{66}$ Autologous infusion of mesenchymal stem cells has been performed in PD patients, and is considered to be safe. This seems promising, and hopefully will be applicable to pediatric patients in the future. ${ }^{67}$

\section{Conclusion}

PD is the modality of choice in children undergoing RRT, until the ultimate goal of renal transplant is reached. Physiologically, the advantages of PD over HD in children are related to high peritoneal membrane surface area per kilogram of body mass compared with adults. From a practical perspective, a greater degree of freedom in children on PD allows home dialysis, school attendance, and engagement in normal everyday activities. In addition, avoidance of the difficulties encountered in the creation and maintenance of adequate vascular HD access is beneficial, reliable HD being especially difficult to maintain in younger patients. PD is also associated with a slower rate of decline in native renal function compared with HD.

A number of factors make decisions about initiating infant dialysis complex, not least ethical considerations. Embarking on RRT in the very young children in particular is a considerable undertaking, and the decision to dialyze is ultimately based on adding to the best interests of the child.

A high standard of preparation and support, tailored to each child and family should be provided by a multidisciplinary team. Active, committed, and well-taught carers are an absolute necessity for PD to be successful.

It is extremely important to maintain the integrity of the peritoneal membrane for as long as possible, especially if there is a significant wait for a renal transplant. Adverse morphological changes occur at the cellular level during the process of PD, including loss of mesothelial cells and fibrosis. The most important factors damaging the peritoneal membrane are episodes of peritonitis, and certain properties of the dialysate such as a low $\mathrm{pH}$, high lactate, and osmolality. These factors increase the synthesis of transforming growth factor beta, which in turn stimulates the production of damaging reactive oxygen species.
The almost inevitable deterioration in peritoneal ultrafiltration properties over time has prompted attempts to develop new approaches to dialysis therapy, aiming to limit these adverse changes. There is evidence that biocompatible solutions are advantageous in promoting membrane integrity, and if available these should be used, especially in younger children and in those in whom a long time on PD is anticipated.

It is imperative that all centers offering pediatric PD monitors attempt to minimize their peritonitis rates. Evidence-based preventative strategies include preimplantation antibiotic prophylaxis, catheter-related interventions (catheter selection, meticulous implantation technique, exit site orientation), acute and chronic exit site care, adherence to contamination protocols, prevention of touch contamination, and patient and trainer training. Attempts should be made to attain root cause analysis when peritonitis or other infections occur, and centers should maintain continuous quality improvement programs aiming to prevent all PD complications. Other common complications may be prevented by following well-described surgical maneuvers such as omentectomy.

Since the emergence of RRT in children, there has been impressive collaboration between centers providing dialysis, and as a result of shared insights, many valuable studies and consensus guidelines have emerged. However, there is a lack of robust systematic studies in newer aspects of pediatric PD, in particular regarding treatment of the damaged peritoneal membrane. The hope is that further long-term studies on all aspects of PD and research on newly designed therapies applied to the pediatric population will add to the evidence base. This will improve the efficacy of PD in children with ESRD and ultimately their quality of life.

\section{Acknowledgement}

Many thanks to Mr Alun Williams, Consultant Pediatric Urologist and Transplant Surgeon, for advice on the section related to laparoscopic-assisted insertion of peritoneal dialysis catheters.

\section{Disclosure}

The authors report no conflicts of interest in this work.

\section{References}

1. Watson AR, Gartland C; European Paediatric Peritoneal Dialysis Working Group. Guidelines by an ad hoc European committee for elective chronic peritoneal dialysis in pediatric patients. Perit Dial Int 2001;21:240-244

2. Tsai HL, Yang LY, Chin TW, et al. Outcome and risk factors for mortality in pediatric peritoneal dialysis. Perit Dial Int. 2010;30:233-239. 
3. Phan J, Stanford S, Zaritsky JJ, DeUgarte DA. Risk factors for morbidity and mortality in pediatric patients with peritoneal dialysis catheters. J Pediatr Surg. 2013;48:197-202.

4. Pruthi R, O`Brien C, Casula A, et al. UK Renal Registry 15th annual report: Chapter 4 demography of the UK paediatric renal replacement therapy population in 2011. Nephrol Clin Pract. 2013;123 Suppl 1: $81-92$.

5. Orlow WN. [Several tests on the resorption in the peritoneal cavity.] Eur J Physiol. 1895;59:170.

6. Pyper RA. Peritoneal dialysis. Ulster Med J. 1948;17:179-187.

7. Tenckhoff H, Schechter H. A bacteriologically safe peritoneal access device. Trans Am Soc Artif Intern Organs. 1968;14:181-187.

8. Devine H, Oreopoulos DG, Izatt S, Mathews R, deVeber GA. The permanent Tenckhoff catheter for chronic peritoneal dialysis. Can Med Assoc J. 1975;113:219-221.

9. Tenckhoff H, Curtis K. Experience with maintenance peritoneal dialysis in the home. Trans Am Soc Artif Intern Organs. 1970;16:90-95.

10. Di Paolo N, Petrini G, Garosi G, Buoncritiani U, Brardi S, Monaci G. A new self-locating peritoneal catheter. Perit Dial Int. 1996;16: 623-627.

11. Twardowski ZJ. Presternal peritoneal catheter. Adv Ren Replace Ther. 2002;9:125-132.

12. Alexander SR, Donaldson LA, Sullivan KE. CAPD/CCPD for children in North America: the NAPRTCS experience. In: Fine RN, Alexander SR, Warady BA, editors. CAPD/CCPD in Children. 2nd ed. Boston, MA, USA: Kluwer Academic; 1998.

13. National Institute for Health and Care Excellence. Peritoneal dialysis in the treatment of stage 5 chronic kidney disease. Jul 2011. NICE clinical guideline 125. Available from: http://www.nice.org.uk/guidance/cg125/ resources/cg125-peritoneal-dialysis-full-guideline3. Accessed May 25, 2015.

14. Rees L, Feather S, Shroff R. Peritoneal dialysis, clinical practice guidelines for children and adolescents. British Association for Paediatric Nephrology; 2008. Available from: http://www.renal.org/ docs/default-source/special-interest-groups/bapn/clinical-standards/ bapn-pd-standards-and-guidelines.pdf?sfvrsn=2. Accessed May 25, 2015.

15. Fischbach M, Warady BA. Peritoneal dialysis prescription in children: bedside principles for optimal practice. Pediatr Nephrol. 2009;24: 1633-1642.

16. Fischbach M, Terzic J, Chauvé S, Laugel V, Muller A, Haraldsson BB. Optimal volume prescription for children on peritoneal dialysis. Perit Dial Int. 2000;20:603-606.

17. Geary D, Bradley A, Warady MD. Peritoneal equilibration test in children. In: Fine RN, Alexander SR, Warady BA, editors. CAPD/CCPD in Children. 2nd ed. Boston, MA, USA: Kluwer Academic; 1998.

18. Aksu N, Yavascan O, Anil M, Orhan DK, Hakan E, Alkan B. A ten-year single-centre experience in children on chronic peritoneal dialysis significance of percutaneous placement of peritoneal dialysis catheters. Nephrol Dial Transplant. 2007;22:2045-2051.

19. Williams AR. Hemodialysis and peritoneal dialysis. In: Wilcox DT, Godbole PP, Koyle MA, editors. Pediatric Urology: Surgical Complications and Management. 1st ed. Hoboken, NJ, USA: Wiley and Sons; 2008

20. Warady BA, Bakkaloglu S, Newland J, et al. Consensus guidelines for the prevention and treatment of catheter-related infections and peritonitis in pediatric patients receiving peritoneal dialysis: 2012 update. Perit Dial Int. 2012;32 Supp1 2:S32-S86.

21. Najmaldin A. Insertion of peritoneal dialysis catheter. In: Najmaldin A, Rothenburg S, Crabbe DC, Beasley S, editors. Operative Endoscopy and Endoscopic Surgery in Infants and Children. London, UK: Hodder Arnold; 2005.

22. Lessin MS, Luks FI, Brem AS, Wesselhoeft CW Jr. Primary laparoscopic placement of peritoneal dialysis catheters in children and young adults. Surg Endosc. 1999;13:1165-1167.

23. Goh YH. Omental folding: a novel laparoscopic technique for salvaging peritoneal dialysis catheters. Perit Dial Int. 2008;28:626-631.
24. Daschner M, Gfrörer S, Zachariuo Z, Mehls O, Schaefer F. Laparoscopic Tenckhoff catheter implantation in children. Perit Dial Int. 2002;22: 22-26.

25. Lindley RM, Williams AR, Fraser N, Shenoy MU. Synchronous laparoscopic-assisted percutaneous endoscopic gastrostomy and peritoneal dialysis catheter placement is a valid alternative to open surgery. J Pediatr Urol. 2013;9:84-89.

26. Keshvari A, Fazeli MS, Meysamie A, Seifi S, Taromloo MK. The effects of previous abdominal operations and intraperitoneal adhesions on the outcome of peritoneal dialysis catheters. Perit Dial Int. 2010;30: 41-45.

27. Paul A, Fraser N, Manoharan S, Williams AR, Shenoy MU. The challenge of maintaining dialysis lines in the under twos. $J$ Pediatr Urol. 2011;7:48-51.

28. Rinaldi S, Sera F, Verrina E, et al. Chronic peritoneal dialysis catheters in children: a fifteen-year experience of the Italian registry of pediatric chronic peritoneal dialysis. Perit Dial Int. 2004;24:481-486.

29. Crompton CH, Balfe JW, Khoury A. Peritoneal dialysis in the prune belly syndrome. Perit Dial Int. 1994;14:17-21.

30. Yildiz N, Memisoglu A, Benzer M, Altuntas U, Alpay H. Can peritoneal dialysis be used in preterm infants with congenital diaphragmatic hernia? J Matern Fetal Neonatal Med. 2013;26:943-945.

31. Twardowski ZJ, Prowant BF, Nochols WK, Nolph KD, Khanna R. Six-year experience with swan neck presternal peritoneal dialysis catheter. Perit Dial Int. 1998;18:598-602.

32. Aksu N, Yavascan O, Anil N, Kara OD, Bal A, Anil AB. Chronic peritoneal dialysis in children with special needs or social disadvantage or both: contraindications are not always contraindications. Perit Dial Int. 2012;32:4:424-430

33. Patel UD, Mottes TA, Flynn JT. Delayed compared with immediate use of peritoneal catheter in pediatric peritoneal dialysis. Adv Perit Dial. 2001;17:253-259

34. Gunasekara WD, Ng KH, Chan YH, et al. Specialist pediatric dialysis nursing outcomes in children on chronic peritoneal dialysis. Pediatr Nephrol. 2010;25:2141-2147.

35. Mitsnefes MM, Laskin BL, Dahhou M, Zhang X, Foster BJ. Mortality risk among children initially treated with dialysis for end-stage kidney disease, 1990-2010. JAMA. 2013;309:1921-1929.

36. Vidal E, Edefonti A, Murer L, et al. Peritoneal dialysis in infants: the experience of the Italian registry of paediatric chronic dialysis. Italian Registry of Paediatric Chronic Dialysis. Nephrol Dial Transplant. 2012;27:388-395.

37. Laakkonen H, Hölttä T, Lönnqvist T, Holmberg C, Rönnholm K. Peritoneal dialysis in children under two years of age. Nephrol Dial Transplant. 2008;23:1747-1753.

38. Schroff R, Rees L, Trompeter R, Hutchinson C, Ledermann S. Long-term outcomes of chronic dialysis in children. Pediatr Nephrol. 2006;21:257-264

39. Lane JC, Warady BA, Feneberg R, et al. Relapsing peritonitis in children who undergo chronic peritoneal dialysis: a prospective study if the international pediatric peritonitis registry. International Pediatric Peritonitis Registry. Clin J Am Soc Nephrol. 2010;6:1041-1046.

40. Williams AJ, Boletis I, Johnson BF, et al. Tenckhoff catheter replacement or intraperitoneal urokinase: a randomised trial in the management of recurrent continuous ambulatory peritoneal dialysis (CAPD) peritonitis. Perit Dial Int. 1989;9;65-67.

41. Bayston R, Fisher LE, Weber K. An antimicrobial modified silicone peritoneal catheter with activity against both Gram-positive and Gramnegative bacteria. Biomaterials. 2009;30:3167-3173.

42. Quinlan C, Cantwell M, Rees L. Eosinophilic peritonitis in children on chronic peritoneal dialysis. Pediatr Nephrol. 2010;25:517-522.

43. Forbes TA, Lunn AJ. Montelukast: a novel therapeutic option in eosinophilic peritonitis. Pediatr Nephrol. 2014;29:1279-1282.

44. Strippoli GF, Tong A, Johnson D, Schena FP, Craig JC. Catheterrelated interventions to prevent peritonitis in peritoneal dialysis: a systematic review of randomized, controlled trials. J Am Soc Nephrol. 2004;15:2735-2746. 
45. [No authors listed]. Nasal mupirocin prevents Staphylococcus aureus exit-site infection during peritoneal dialysis. Mupirocin Study Group. J Am Soc Nephrol. 1996; 7:2403-2408.

46. Wong KK, Lan LC, Lin SC, Tam PK. Small bowel herniation and gangrene from peritoneal dialysis catheter exit site. Pediatr Nephrol. 2003;18:301-302.

47. Ladd AP, Breckler FD, Novotny NM. Impact of primary omentectomy on longevity of peritoneal dialysis catheters in children. Am J Surg. 2011;201:401-404.

48. Bae IE, Chung WK, Choi ST, Kang J. Laparoscopic internal fixation is a viable alternative option for continuous peritoneal dialysis catheter insertion. J Korean Surg Soc. 2012;83:381-387.

49. Leblanc M, Ouimet D, Pichette V. Dialysate leaks in peritoneal dialysis. Semin Dial. 2001;14:50-54.

50. Frost JH, Bagul A. A brief recap of tips and surgical manoeuvres to enhance optimal outcome of surgically placed peritoneal dialysis catheters. Int J Nephrol. 2012;2012:251584.

51. Robson WL, Leung AK, Putnins RE, Boag GS. Genital edema in children on continuous ambulatory peritoneal dialysis. Child Nephrol Urol. 1990;10:205-210.

52. Yang PJ, Lee CY, Yeh CC, et al. Mini-laparotomy implantation of peritoneal dialysis catheters: outcome and rescue. Perit Dial Int. 2010;30;513-518.

53. Dönmez O, Aladag S, Cigerdelen N, Kocak S. Outcome in children on chronic peritoneal dialysis. Adv Perit Dial. 2003;19:269-272.

54. Borzych D, Ley S, Schaefer F, et al. Dialysate leakage into pericardium in an infant on long-term peritoneal dialysis. Pediatr Nephrol. 2008;23: 335-338.

55. Cho HY, Lee BS, Kang CH, et al. Hydrothorax in a patient with Denys-Drash syndrome associated with a diaphragmatic defect. Pediatr Nephrol. 2006;21:1909-1912.

56. Chao SH, Tsai TJ. Partial replantation of Tenckhoff catheters to treat intractable exit-site/tunnel infection. J Am Soc Nephrol. 1996;7: 1085-1087.

57. van Asseldonk JP, Schröder CH, Severijnen RS, de Jong MC, Monnens LA. Infectious and surgical complications of childhood continuous ambulatory peritoneal dialysis. Eur J Pediatr. 1992;151:377-380.
58. Dönmez O, Durmaz O, Ediz B, Cigerdelen N, Kocak S. Catheter-related complications in children on chronic peritoneal dialysis. Adv Perit Dial. 2005;21:200-203.

59. Stringel G, McBride W, Weiss R. Laparoscopic placement of peritoneal dialysis catheters in children. J Pediatr Surg. 2007;43:857-860.

60. Araki Y, Hataya H, Tanaka Y, et al. Long-term peritoneal dialysis is a risk factor of sclerosing encapsulating peritonitis for children. Perit Dial Int. 2000;20:445-451.

61. Mateijsen MA, van der Wal AC, Hendriks PM, et al. Vascular and interstitial changes in the peritoneum of CAPD patients with peritoneal sclerosis. Perit Dial Int. 1999; 19:517-525.

62. Afthentopoulos IE, Passadakis P, Oreopoulos PG, Bagman S. Sclerosing peritonitis in CAPD patients: one centre's experience and review of the literature. Adv Ren Replace Ther. 1998;5:157-167.

63. Sigaroudinia MO, Baillie C, Ahmed S, Mallucci C. Sclerosing encapsulating peritonitis-a rare complication of ventriculoperitoneal shunts. J Pediatr Surg. 2008;43:E31-E33.

64. Hamilton AJ, Pruthia R, Maxwell H, et al. UK Renal Registry 17th Annual Report: Chapter 9. Clinical, haematological and biochemical parameters in patients receiving renal replacement therapy in paediatric centres in the UK in 2013: national and centre-specific analyses. Available from: http://research-information.bristol.ac.uk/en/ publications/uk-renal-registry-17th-annual-report\%289e5a9714-abb24887-8f48-7bdd2eec34ae\%29/export.html. Accessed May 25, 2015.

65. North American Pediatric Renal Trials and Collaborative Studies 2011 Annual Dialysis Report. 5-1 to 5-7. Available from: https://web. emmes.com/study/ped/annlrept/annualrept2011.pdf. Accessed May 25, 2015.

66. Ueno T, Ayumu N, Shigehiro D, et al. Mesenchymal stem cells ameliorate experimental peritoneal fibrosis by suppressing inflammation and inhibiting TGF- $\beta 1$ signaling. Kidney Int. A 2013;84: 297-307.

67. Di Paolo N, Vanni L, Sacchi G. Autologous implant of peritoneal mesothelium in rabbits and man. Clin Nephrol. 1990;34:179-184.

\section{Publish your work in this journal}

The International Journal of Nephrology and Renovascular Disease is an international, peer-reviewed open-access journal focusing on the pathophysiology of the kidney and vascular supply. Epidemiology, screening, diagnosis, and treatment interventions are covered as well as basic science, biochemical and immunological studies. The journal welcomes

\section{Dovepress}

original research, clinical studies, reviews \& evaluations, expert opinion and commentary, case reports and extended reports. The manuscript management system is completely online and includes a very quick and fair peerreview system, which is all easy to use. Visit http://www.dovepress.com/ testimonials.php to read real quotes from published authors 